\title{
It takes two to tango: Right ventricular failure after left ventricular surgery
}

\author{
Patrick M. McCarthy, MD
}

\footnotetext{
From the Bluhm Cardiovascular Institute, Northwestern Memorial Hospital; and the Division of Cardiac Surgery, Department of Surgery, Feinberg School of Medicine, Northwestern University, Chicago, Ill.

Disclosures: P.M.M. discloses connections with Edwards Lifesciences (consultant, royalties, and intellectual property) and Abbott Vascular (consultant).

Received for publication Dec 22, 2016; accepted for publication Jan 2, 2017; available ahead of print Jan 31, 2017. Address for reprints: Patrick M. McCarthy, MD, School of Medicine, Northwestern University, Division of Cardiac Surgery, 201 E Huron St, Suite 11-140, Chicago, IL 60611-2908 (E-mail: pmccart@nm.org).

J Thorac Cardiovasc Surg 2017;153:843-4

$0022-5223 / \$ 36.00$

Copyright (c) 2017 by The American Association for Thoracic Surgery

http://dx.doi.org/10.1016/j.jtcvs.2017.01.002
}

When a colleague refers a patient for heart surgery, how often do we ask, "What is the right ventricular (RV) ejection fraction?" I've never asked. We probably should pay closer attention, as evidenced by the article in this issue of the Journal by Couperus and colleagues. ${ }^{1}$ Quantifying RV function is not easy, and if the tricuspid valve is the "forgotten valve," then the RV is the "forgotten ventricle." RV geometry is complex, the afterload and preload can shift dramatically, transthoracic echocardiography is technically challenging, and even 3-dimensional echocardiography and magnetic resonance imaging may not provide precise data such as we use to assess left ventricular function and volumes. Aphoristically, not everything that matters can be measured, and not everything that is measured matters. RV function is hard to measure, but it matters. Various studies have indicated that patients with cardiomyopathy and severe RV dysfunction have a worse prognosis, ${ }^{2,3} \mathrm{RV}$ dysfunction before mitral surgery adversely affects late outcomes, ${ }^{4} \mathrm{RV}$ dysfunction affects outcomes after aortic valve operations and transcatheter aortic valve replacement, ${ }^{5}$ and $\mathrm{RV}$ dysfunction has previously been shown to predict long-term outcome in patients with heart failure undergoing surgical left ventricular restoration. ${ }^{6}$ It seems intuitively obvious. RV dysfunction can cause low cardiac output; elevated right heart pressures may cause liver and renal dysfunction with ascites and edema; and the progressive downward spiral from tricuspid regurgitation gradually creates more RV dilatation and dysfunction.

So, what did we learn from this study? The 30-day mortality was high $(11 \%)$, and Couperus and colleagues ${ }^{1}$ appear to have operated on a lot of patients with RV dysfunction (39\% had $\geq 1$ parameters). The Surgical Treatment for Ischemic Heart Failure (STICH) trial had a 30-day mortality of $13.6 \%$ in patients with RV dysfunction and a 30 -day mortality of $4.7 \%$ in those without RV dysfunction. ${ }^{7}$ When I was at the Cleveland Clinic, we were avoiding

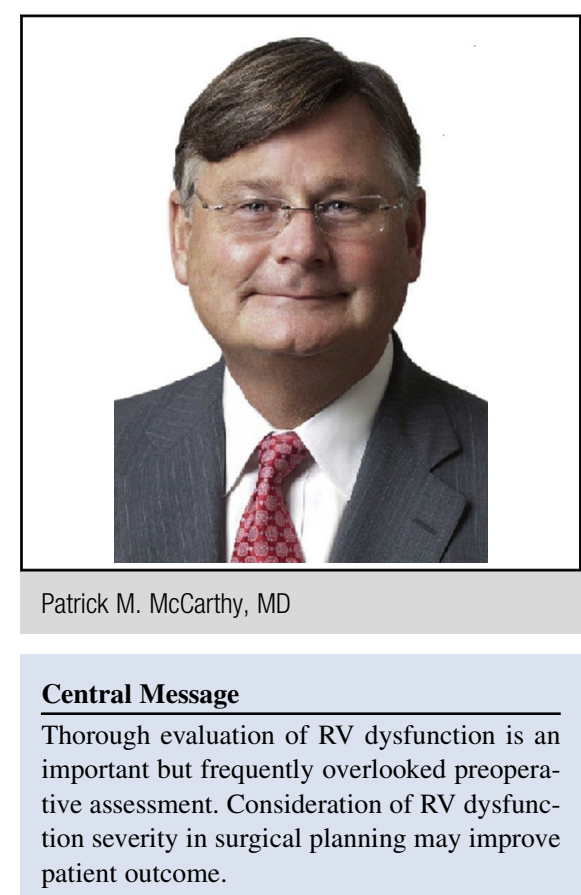

See Article page 845 .

patients with RV dysfunction, which we considered a contraindication to this operation, and we achieved a $1 \%$ 30-day mortality. ${ }^{8}$

What didn't we learn from this study? Since Couperus and colleagues ${ }^{1}$ have only reported 30-day results, we don't know whether RV dysfunction impacts late survival as well. Perhaps nonfatal but ongoing RV dysfunction limits late clinical improvement and quality of life. Or, more optimistically, RV dysfunction may improve, as it does in some patients with cardiomyopathy, and survival and clinical outcomes will improve as well.

What do we do differently because of this article? For patients undergoing left ventricular reconstruction, further testing of RV function is warranted. Perhaps those with the most advanced RV dysfunction should be turned down for conventional surgery, and transplantation or mechanical support should be considered. Since our measurement techniques are limited, however, perhaps we should use our clinical clues (liver dysfunction, renal dysfunction, severe edema and ascites that do not respond to diuretics, etc) to select patients. We need more data and studies like this. We need to pay closer attention, because in the dance between the two ventricles, it takes two to have a successful tango. 


\section{References}

1. Couperus LE, Delgado V, Palmen M, van Vessem ME, Braun J, Fiocco M, et al. Right ventricular dysfunction affects survival after surgical left ventricular restoration. J Thorac Cardiovasc Surg. 2017;153:845-52.

2. Gulati A, Ismail TF, Jabbour A, Alpendurada F, Guha K, Ismail NA, et al. The prevalence and prognostic significance of right ventricular systolic dysfunction in nonischemic dilated cardiomyopathy. Circulation. 2013;128: 1623-33.

3. Merlo M, Gobbo M, Stolfo D, Losurdo P, Ramani F, Barbati G, et al. The prognostic impact of the evolution of RV function in idiopathic DCM. JACC: Cardiovasc Imaging. 2016;9:1034-42.

4. Le Tourneau T, Deswarte G, Lamblin N, Foucher-Hossein C, Fayad G, Richardson M, et al. Right ventricular systolic function in organic mitral regurgitation: impact of biventricular impairment. Circulation. 2013;127: 1597-608.
5. Ito S, Pislaru SV, Soo WM, Huang R, Greason KL, Mathew V, et al. Impact of right ventricular size and function on survival following transcatheter aortic valve replacement. Int J Cardiol. 2016;15:269-74.

6. Garatti A, Castelvecchio S, Di Mauro M, Bandera F, Guazzi M, Menicanti L. Impact of right ventricular dysfunction on the outcome of heart failure patients undergoing surgical ventricular reconstruction. Eur J Cardiothorac Surg. 2015;47: 333-40; discussion 340.

7. Kukulski T, Lilin S, Racine N, Gradinac S, Panza JA, Velazquez EJ, et al. Surgical Treatment for Ischemic Heart Failure Investigators. Implication of right ventricular dysfunction on long-term outcome in patients with ischemic cardiomyopathy undergoing coronary artery bypass grafting with or without surgical ventricular reconstruction. J Thorac Cardiovasc Surg. 2015;149:1312-21.

8. O’Neill JO, Starling RC, McCarthy PM, Albert NM, Lytle BW, Navia J, et al. The impact of left ventricular reconstruction on survival in patients with ischemic cardiomyopathy. Eur J Cardiothorac Surg. 2006;30:753-61. 